\title{
PROJETO DE LETRAMENTO NA EDUCAÇÃO INFANTIL: PRÁTICAS ORAIS E ESCRITAS
}

\author{
PROYECTO DE ALFABETIZACIÓN/ LETRAMENTO EN LA EDUCACIÓN \\ INFANTIL: PRÁCTICAS ORALES Y ESCRITAS
}

LITERACY PROJECT IN KINDERGARTEN: ORAL AND WRITTEN PRACTICES

\author{
Ariane RANZANI ${ }^{1}$ \\ Patrícia PEREIRA ${ }^{2}$
}

RESUMO: O presente artigo visa ampliar a reflexão sobre práticas orais e escritas desenvolvidas na Educação Infantil a partir de um projeto de letramento que possibilitou às crianças ampliarem suas experiências culturais ao transitar por diferentes gêneros discursivos. O trabalho pedagógico envolveu crianças da Educação Infantil com a idade entre 4 e 6 anos. Tendo como embasamento teórico a Psicologia Histórico-Cultural (LEONTIEV, 1978a, 1978b, 2014a, 2014b; VYGOTSKI, 1995) e os Estudos do Letramento (KLEIMAN, 2000; TINOCO, 2008), foi possível concluir que a proposta de propiciar, desde a Educação Infantil, o acesso da criança a diferentes práticas orais e escritas, favorece que ela se sinta letrada, ao mesmo tempo em que possibilita que ela assuma diferentes papeis sociais e se aproprie dos conhecimentos elaborados sócio-historicamente.

PALAVRAS-CHAVE: Educação infantil. Letramentos. Intencionalidade educativa.

RESUMEN: Este trabajo busca ampliar la reflexión sobre prácticas orales y escritas desarrolladas en la Educación Infantil a partir de un proyecto de alfabetización/letramento que posibilitó a los niños ampliar sus experiencias culturales al transitar por diferentes géneros discursivos. El trabajo pedagógico involucró a niños de Educación Infantil a la edad entre 4 y 6 años. En el caso de la Psicología Histórico-Cultural (LEONTIEV, 1978a, 1978b, 2014a, 2014, VYGOTSKI, 1995) y los Estudios sobre la nueva alfabetización (KLEIMAN, 2000, TINOCO, 2008), fue posible concluir que la propuesta de propiciar, desde la Educación Infantil, el acceso del niño a diferentes prácticas orales y escritas, favorece que él se sienta letrado, al mismo tiempo que posibilita que asuma diferentes papeles sociales y se apropie de los conocimientos elaborados socio-históricamente.

PALABRAS CLAVE: Educación infantil. Alfabetizaciones. Letramentos. Intencionalidad educativa.

\footnotetext{
${ }^{1}$ Prefeitura Municipal de São Carlos (PMSC), São Carlos - São Paulo - Brasil. Professora da Educação Infantil da Prefeitura Municipal de São Carlos. Doutora em Linguística pela Universidade Federal de São Carlos (UFSCar). ORCID: <https://orcid.org/0000-0002-0822-7969>. E-mail: arianeranzani12@ gmail.com

2 Prefeitura Municipal de São Carlos (PMSC), São Carlos - São Paulo - Brasil. Professora de Educação Infantil da Prefeitura Municipal de São Carlos. Mestre em Educação pela Universidade Federal de São Carlos (UFSCar). Especialista em Educação Infantil, pela Universidade Central Paulista (UNICEP). ORCID: <https://orcid.org/0000-0001-8164-215X>. E-mail: patricinha.pereira@yahoo.com.br
}

Temas em Educ. e Saúde, Araraquara, v. 14, n. 2, p. 302-317, jul/dez, 2018. 
ABSTRACT: This paper show the reflection about oral and written practices developed in kindergarten from a literacy project that enabled children to expand their cultural experiences with discursive genres. The pedagogical work involved children from kindergarten between 4 and 6 years old. Historical-Cultural Psychology (LEONTIEV, 1978a, 1978b, 2014a, 2014b; VYGOTSKI, 1995) and the New Literacy Studies (KLEIMAN, 2000; TINOCO, 2008) were the theoretical basis of this study. It is concluded that the child's access to different oral and written practices favors them to feel literate, while allowing her to assume different social roles and to appropriate the socio-historically elaborated knowledge.

KEYWORDS: Kindergarten. Literacy. Intentionality Educational.

\section{Introdução}

Atualmente, existem inúmeras evidências empíricas sobre os efeitos positivos da leitura literária no desenvolvimento infantil, bem como nas aprendizagens iniciais relacionadas à leitura e à escrita, de acordo com Cardoso e Sepúlveda (2015, p. 83). As autoras esclarecem ainda que:

Em relação à oralidade, tem-se documentado que as crianças pré-escolares que assistem atos de leitura de contos são capazes de reproduzi-los ou recontá-los, isto é, são capazes de produzir textos com as características próprias da linguagem escrita (Blanche-Benveniste, 1982; Pappas e Browne, 1987a, 1987b; Teberosky, 1988, 1989, 1993). A análise dessas produções tem mostrado que a situação repetida de leituras e recontos orais oferece às crianças oportunidades para se apropriarem das formas de expressão próprias dos textos escritos. Nos seus recontos, aparecem características como a formulação de frases nominais elaboradas, com adjetivos atributivos e séries de nomes, o uso de frases adverbiais, expressões ou palavras literárias, citações diretas, expressões formulárias para o início e o final da narração, entre outras. Em relação à escrita, estudos recentes de intervenção com crianças pré-escolares provam que as situações de ensino baseadas na leitura de textos poéticos e de jogos de linguagem em livros de literatura infantil promovem a conceituação do escrito, avaliado em tarefas de consciência fonológica, conhecimento de letras e escrita [...] (CARDOSO, SEPÚLVEDA, 2015, p. 83-84)

Atrelado às práticas significativas com a leitura e a escrita na Educação Infantil está o trabalho com projetos que independentemente de sua adjetivação (escolar, de trabalho, de ação social, interdisciplinar, pedagógico, educacional, de letramento), busca uma prática recontextualizada e requer reflexão dos envolvidos, diferentes espaços e momentos, motivações e busca de metas pré-definidas, conforme afirma Tinoco (2008).

Considerando o que foi exposto e que, de acordo com as Diretrizes Curriculares Nacionais para a Educação Infantil (DCNEI), o currículo é um conjunto de práticas que visam "[...] articular as experiências e os saberes das crianças com os conhecimentos que fazem 
parte do patrimônio cultural, artístico, ambiental, científico e tecnológico, de modo a promover o desenvolvimento integral de crianças de 0 a 5 anos de idade.” (BRASIL, 2010, p. 12) e que a proposta pedagógica de uma instituição de Educação Infantil deve ter como objetivo garantir à criança o "[...] acesso a processos de apropriação, renovação e articulação de conhecimentos e aprendizagens de diferentes linguagens, assim como o direito [...] à brincadeira, à convivência e à interação com outras crianças" (BRASIL, 2010, p. 18), além de contemplar os direitos de aprendizagem propostos na Base Nacional Comum Curricular (BNCC) - conviver, brincar, participar, explorar, expressar e conhecer-se (BRASIL, 2018), é que desenvolvemos o projeto apresentado a seguir.

\section{Algumas palavras sobre o contexto onde foi desenvolvido o projeto}

O projeto "Compartilhando histórias, conhecendo pessoas", que será abordado nas próximas seções deste artigo, foi realizado no CEMEI Prof. Paulo Freire, instituição pública municipal de Educação Infantil que atende 201 crianças de 0 a 6 anos em período parcial (manhã ou tarde) e 34 crianças de 0 a 3 anos em período integral. Em 2018, ano em que foi desenvolvido o projeto, a unidade escolar contava com 21 turmas, das quais 5 turmas funcionavam no período da manhã (Fase 2, Fase 3, Fase 4, Fase 5 e Fase 6), 8 no período da tarde e 4 no integral. As turmas do período da manhã eram as seguintes: Fase 2 (1 turma), Fase 3 (1 turma), Fase 4 (1 turma), Fase 5 ( 1 turma) e Fase 6 (1 turma). As turmas do período da tarde eram: Fase 1 (1 turma), Fase 2 (1 turma), Fase 3 (1 turma), Fase 4 (2 turmas), Fase 5 ( 1 turma) e Fase 6 (1 turma). As turmas que funcionavam em período integral eram Fase 1 (1 turma), Fases 2 (2 turmas) e Fase 3 (1 turma).

O projeto foi desenvolvido com as crianças das turmas das Fases 5 e 6 do período da manhã. Essas turmas eram compostas por 19 crianças entre 4 e 5 anos de idade e por 21 crianças entre 5 e 6 anos, respectivamente, e por duas professoras (autoras deste trabalho), sendo que uma delas contava com apoio, em 2 dias na semana, de 3 estagiários dos cursos de Educação Especial e Linguística.

Nossa concepção de criança está intimamente relacionada à concepção apresentada pela BNCC:

[...] como ser que observa, questiona, levanta hipóteses, conclui, faz julgamentos e assimila valores e que constrói conhecimentos e se apropria do conhecimento sistematizado por meio da ação e nas interações com o mundo físico e social não deve resultar no confinamento dessas aprendizagens a um processo de desenvolvimento natural ou espontâneo. Ao 
contrário, impõe a necessidade de imprimir intencionalidade educativa às práticas pedagógicas na Educação Infantil, tanto na creche quanto na préescola (BRASIL, 2018, p. 36, grifo do autor).

Também está consonante com a definição de criança anteriormente expressa pelas Diretrizes Curriculares Nacionais da Educação Infantil (DCNEI), onde ela é compreendida como sujeito histórico e de direitos, que, nas interações, relações e práticas cotidianas que vivencia, constrói sua identidade pessoal e coletiva, brinca, imagina, fantasia, deseja, aprende, observa, experimenta, narra, questiona e constrói sentidos sobre a natureza e a sociedade, produzindo cultura (BRASIL, 2010).

\section{Compartilhando histórias, conhecendo pessoas...}

Foi a partir da consideração de que a linguagem escrita como instrumento complexo da cultura humana (VYGOTSKI, 1995) requer uma aprendizagem escolar que surgiu o projeto "Compartilhando histórias, conhecendo pessoas" com a intenção de desenvolver atividades de leitura e escrita, no contexto da Educação Infantil, enquanto práticas culturais, onde o livro era contado. Acreditamos que tanto o desenvolvimento da criança quanto o desenvolvimento da linguagem são construídos historicamente através da inter-relação entre os indivíduos e o meio social no qual estão inseridos (BRASIL, 2016).

Assim, a princípio, foi realizado um levantamento do conhecimento das crianças sobre as formas de se enviar mensagens e recados para outras pessoas que se encontram distantes. Dentre as respostas dadas pelas elas estavam: carta, celular (Whatsapp), bilhete, computador.

Considerando a empolgação das crianças, perguntamos se elas gostariam de fazer novos amigos, escrevendo uma carta para crianças de outras turmas e escolas. De imediato a resposta foi afirmativa, porém, elas não tinham noção de como começar. Diante disso, o livro "Felpo Filva" (FURNARI, 2006) foi utilizado como elemento norteador para as crianças conhecerem o gênero carta, mais especificamente, o conteúdo temático, a estrutura composicional e o estilo (BAKHTIN, 1997), além de sua função social. Primeiramente, elas assistiram a um vídeo (YOUTUBE) sobre a história do livro. Devido a grande diferença entre a faixa etária das crianças e de indicação de leitura do livro, a história não foi apresentada em sua totalidade, foi lida apenas a parte da troca de correspondências entre os personagens principais.

Após o vídeo, conversamos sobre os personagens da história (Felpo e Charlô) e os motivos que fizeram com que eles escreverem suas cartas. Desse modo, como forma de estabelecer laços de amizade, enquanto a turma da Fase 5 escreveu sua primeira carta para 
crianças da Fase 6 da própria escola, esta turma escreveu cartas para quatro turmas de outras escolas três municipais (Foto 1). Nessas primeiras cartas todos fizeram questão de registrar seu nome, ainda que não convencionalmente e pediram para a professora tirar uma foto com celular para colocar junto com a mensagem (Foto 2). Na Fase 5, uma criança foi eleita o carteiro do dia e entregou a correspondência para a professora da outra turma, na Fase 6 a professora levou as cartas até os Correios.

Foto 1- Primeiras cartas escritas coletivamente pela Fase 6

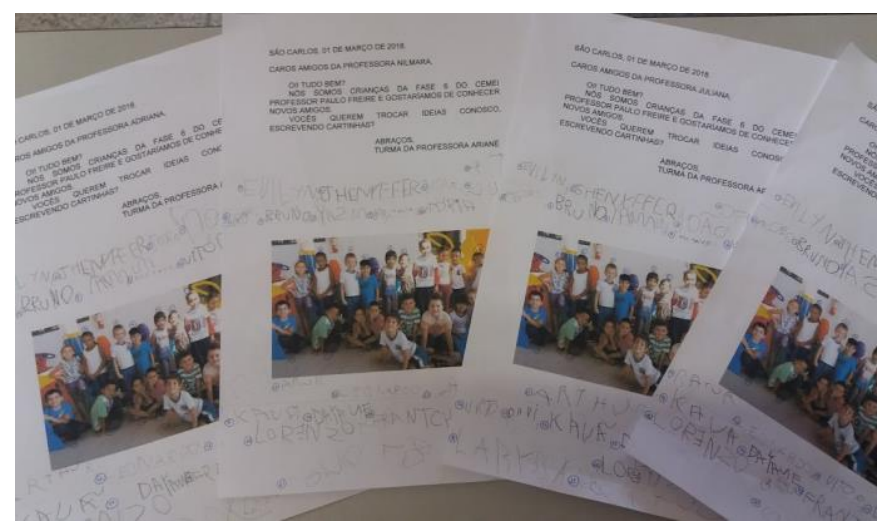

Fonte: Acervo pessoal das autoras

Foto 2 - Primeira carta escrita coletivamente pela Fase 5

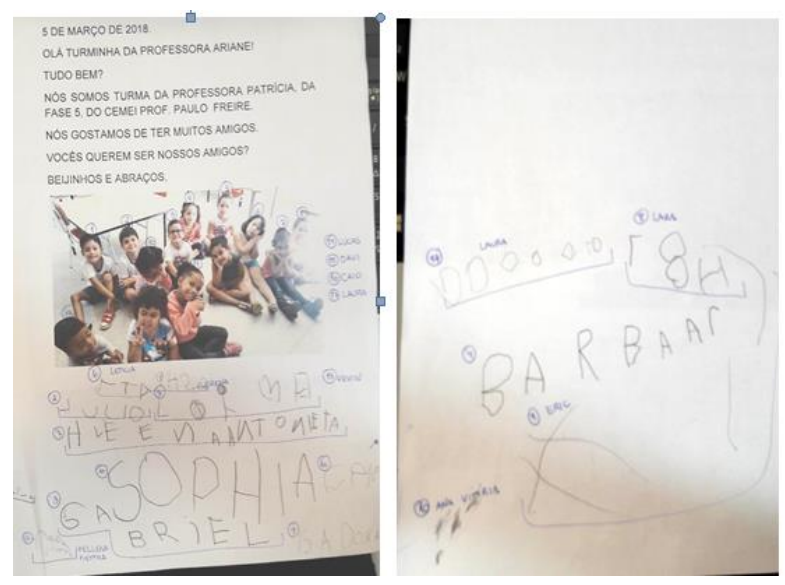

Fonte: Acervo pessoal das autoras

A grande surpresa foi que a primeira carta recebida pelas crianças da Fase 6 foi de amigos de uma turma para a qual, a princípio, elas não haviam escrito nada. Passados alguns dias, a resposta da carta chegou para as crianças da Fase 5 que ficaram muito felizes com a leitura (Foto 3). 
Foto 3 - Carta, envelope e joguinho enviado pela turma da Fase 6 para a da Fase 5

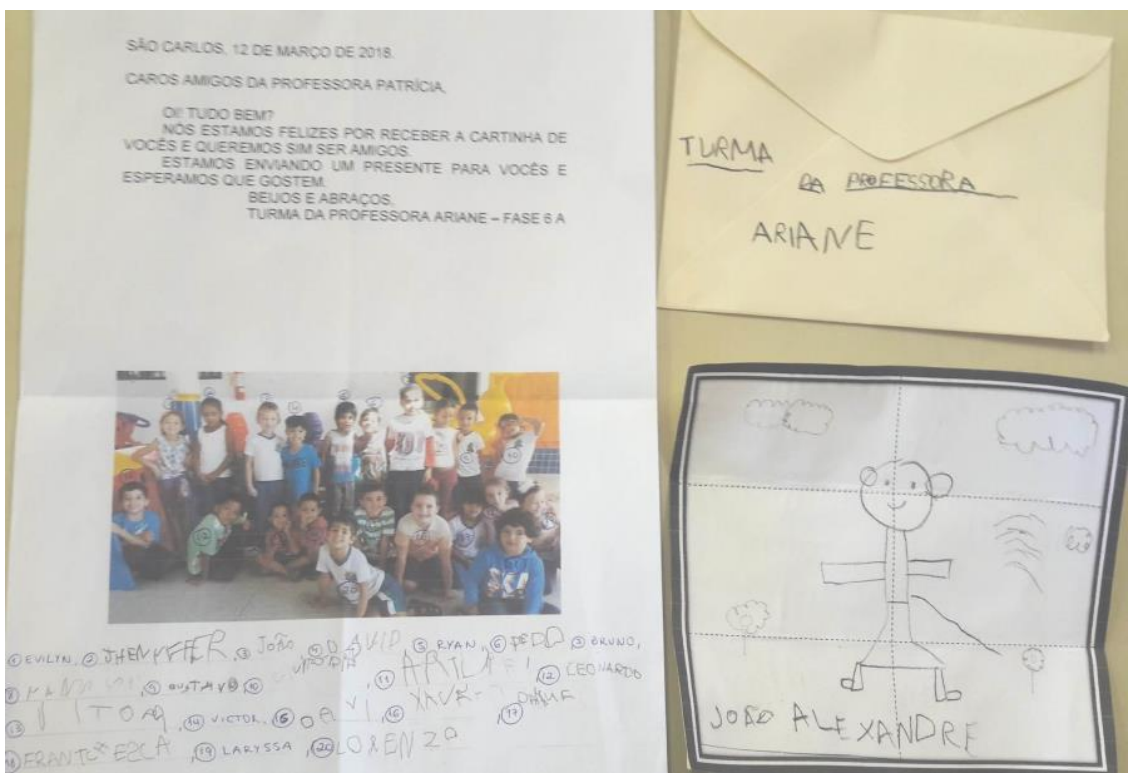

Fonte: Acervo pessoal das autoras

Num outro momento do projeto, considerando a empolgação da turma, com o Felpo (lembravam dele durante as brincadeiras e quando alguém estava triste, pois o personagem era triste por ter problemas em suas orelhas, da amizade dele com a Charlô e faziam os bolinhos do Felpo durante suas brincadeiras com a areia do parque), resolvemos contar a história do "Felpo Filva" novamente, dessa vez com o portador em mãos. Nesse dia, a história foi contada até o momento em que a Charlô pedia a receita dos bolinhos da avó do Felpo para ele, por meio de carta e sugerimos: "Por que nós também não escrevemos para o Felpo e pedimos a receita dos bolinhos da avó dele para nós fazermos"?

Os olhinhos das crianças brilharam e algumas disseram:

“_O Felpo existe de verdade?”

"_Será que ele vai responder a nossa carta?"

Respondemos que o Felpo existia sim, estimulando ainda mais o imaginário delas e que o Felpo não poderia responder, se nós não enviássemos a carta com o endereço da nossa escola. Assim, mais uma carta foi escrita, dessa vez o remetente foi o "QUERIDO FELPO”.

Passaram-se alguns dias e a carta-resposta do "QUERIDO FELPO" (Foto 4) chegou (escrevemos como se fosse o personagem da história): 
Foto 4 - Carta escrita pelo Felpo

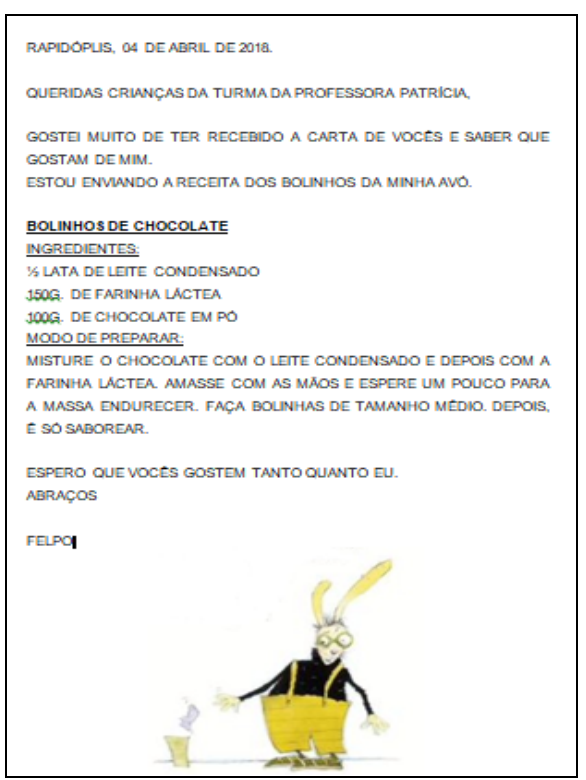

Fonte: Acervo pessoal das autoras

Lemos a carta onde o Felpo (Foto 4) dizia estar muito feliz por ter novos amigos e com a receita dos bolinhos de chocolate de sua avó. Logo uma das crianças disse:

“_Por que a gente não faz os bolinhos da avó do Felpo aqui na escola?”.

“_Claro que a gente pode fazer... mas, por que não escrevemos uma carta para a turma da professora Ariane para contarmos que recebemos uma carta do Felpo com a receita dos bolinhos e perguntamos se eles não querem nos ajudar a fazer?”

“_Legal!”

Novo alvoroço na sala. Nova carta, novamente as assinaturas de todas as crianças (elas fizeram questão de cada uma escrever seu próprio nome ao invés de colocar TURMA FASE 5A, com melhora perceptível na escrita), novo carteiro e o relato para os pais e responsáveis de que haviam recebido uma carta do Felpo.

Ao receber a carta, as crianças da Fase 6 prontamente aceitaram o convite e foram conversar com uma das merendeiras para saber quais ingredientes a escola dispunha e quais precisariam providenciar. Esse fato motivou uma nova carta resposta para a Fase 5 (Foto 5). 
Foto 5 - Carta resposta sobre os bolinhos do Felpo

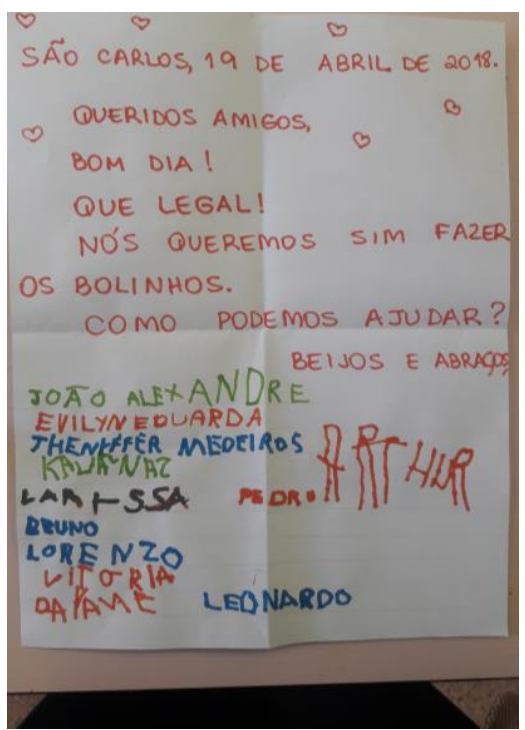

Fonte: Acervo pessoal das autoras

Sem dúvida o personagem e a história do Felpo despertou o interesse das crianças... Assim, o projeto teve uma mudança de rumo: a turma da Fase 5 criou um boneco do Felpo e a turma da Fase 6 criou uma Charlô, ambos com TNT, a partir do desenho de uma das crianças de cada turma e elas mesmas ajudaram a enchê-los de espuma de almofada e manta acrílica (Fotos 6, 7, 8 e 9). As turmas teriam os seus Felpo e Charlô e eles poderiam ir visitar as crianças.

Fotos 6 e 7 - Desenho/ molde e confecção do boneco Felpo

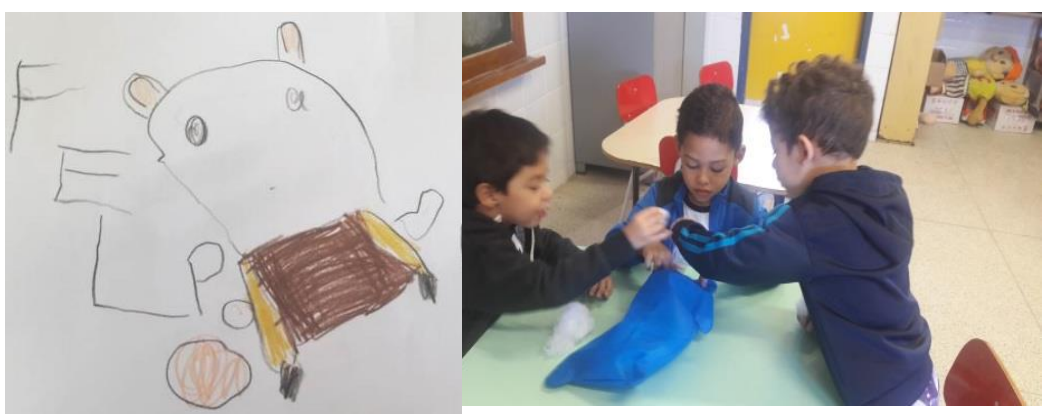

Fonte: Acervo pessoal das autoras 
Fotos 8 e 9 - Desenho/ molde e boneca Charlô

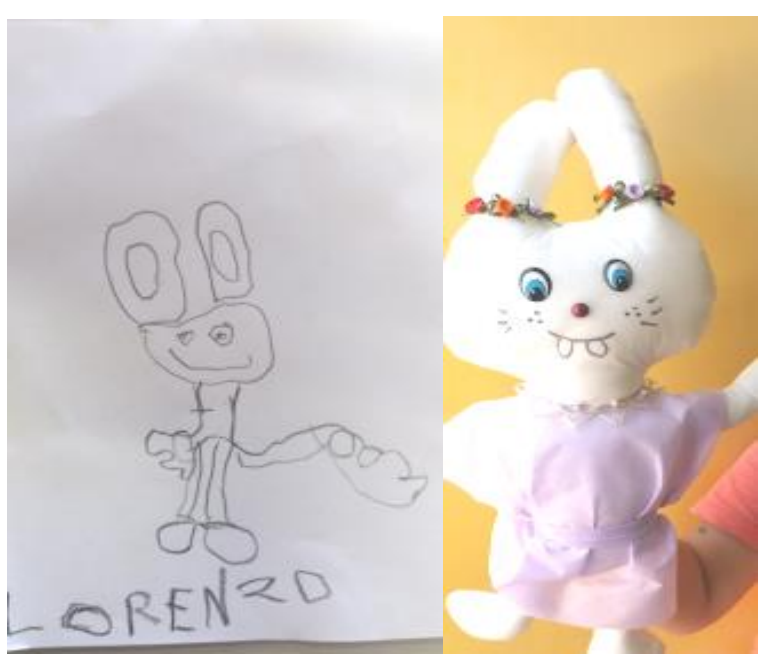

Fonte: Acervo pessoal das autoras

Mas, para que as visitas começassem, as famílias deveriam ser avisadas. A sugestão das crianças foi:

“_Por que não escrevemos uma carta contando do Felpo?”

Então, escrevemos uma carta para a QUERIDA FAMÍLIA, avisando sobre os cuidados a serem tomados com o visitante (Fotos 10 e 11).

Fotos 10 e 11 - Cartas sobre as visitas dos bonecos às famílias
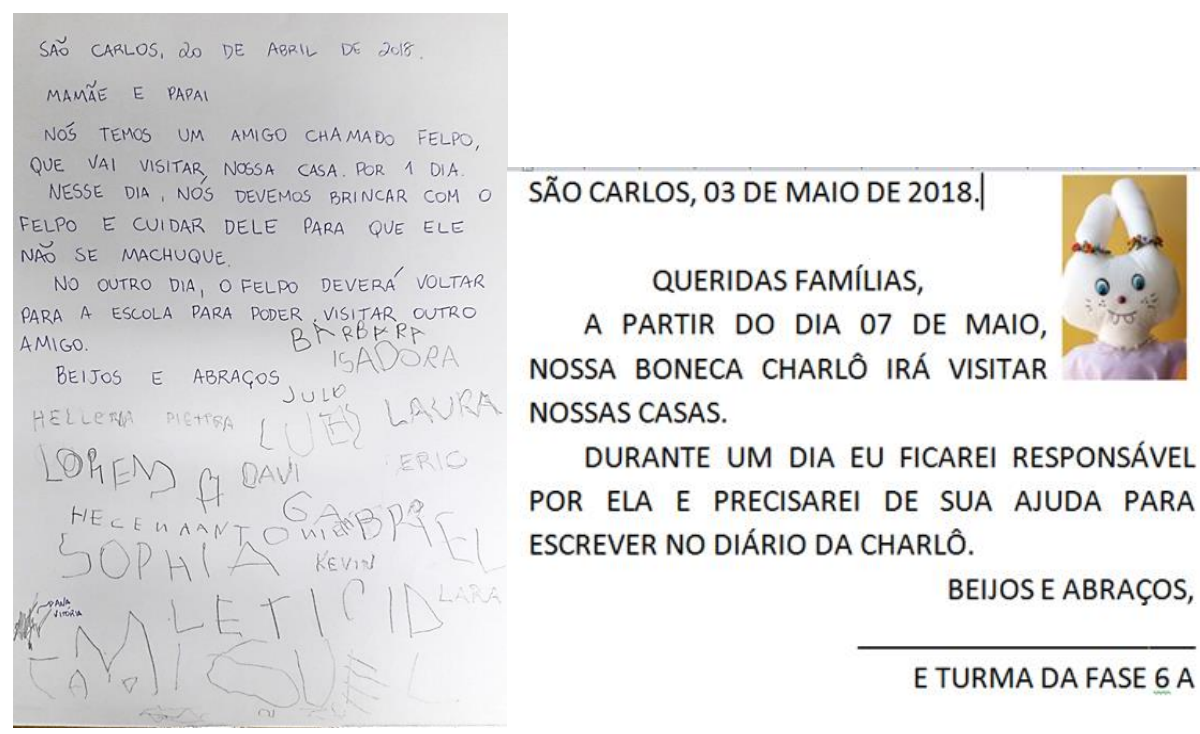

E TURMA DA FASE 6 A

Fonte: Acervo pessoal das autoras 
Depois disso, muitos pais procuraram as professoras para falar sobre a empolgação de seus filhos com relação a visita do Felpo. Alguns relataram que até procuraram a história na internet para saber um pouco mais.

A organização das visitas foi realizada por sorteio: cada dia uma criança levaria o Felpo para casa e deveria cuidar, brincar e trazê-lo de volta no dia seguinte (Foto 12). Contudo, no primeiro dia de passeio aconteceu um acidente, relatados pela mãe e pela criança no dia seguinte: $\mathrm{O}$ Felpo havia sido atropelado de verdade, mas estava bem, na medida do possível (o tecido havia furado e ele estava com marcas de pneus que não foram possíveis de serem removidas, apesar dos cuidados da mãe e desespero da menina).

Foto 12: Criança sorteada para levar o Felpo para casa

Fonte: Acervo pessoal das autoras

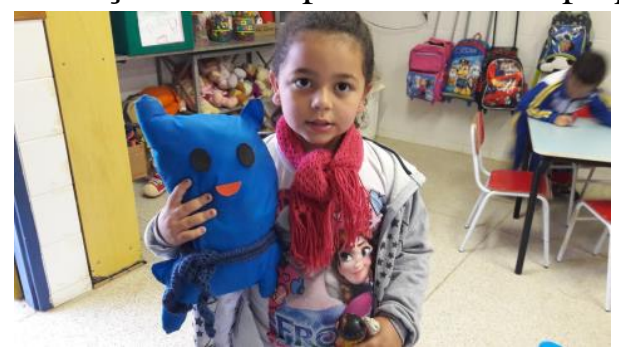

Diante do fato, decidimos criar diários (assim como o "Diário da Turma" que, todos os dias, era escrito pelas crianças da Fase 6) para o Felpo e para a Charlô, onde as famílias pudessem participar, registrando "As aventuras do Felpo" e "As aventuras da Charlô" no dia da visita para compartilhar com as demais crianças no outro dia.

Os registros nos diários são feitos pelas famílias e pelas crianças. Neles aparecem: relatos escritos, desenhos e fotos como podemos observar a seguir tanto no Diário do Felpo quanto da Charlô, conforme podemos observar a seguir: 
Fotos 13,14 e 15 - Registros feitos no diário do Felpo

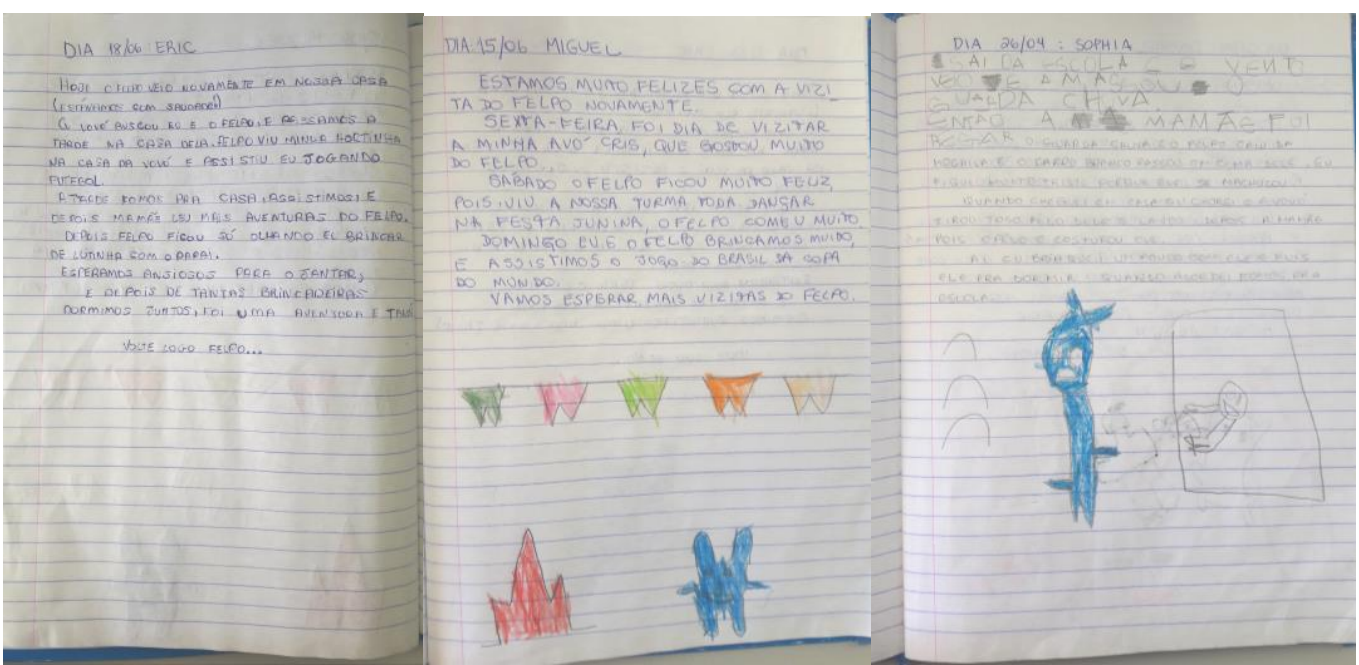

Fonte: Acervo pessoal das autoras

Fotos 16, 17 e 18 - Registros feitos no diário da Charlô
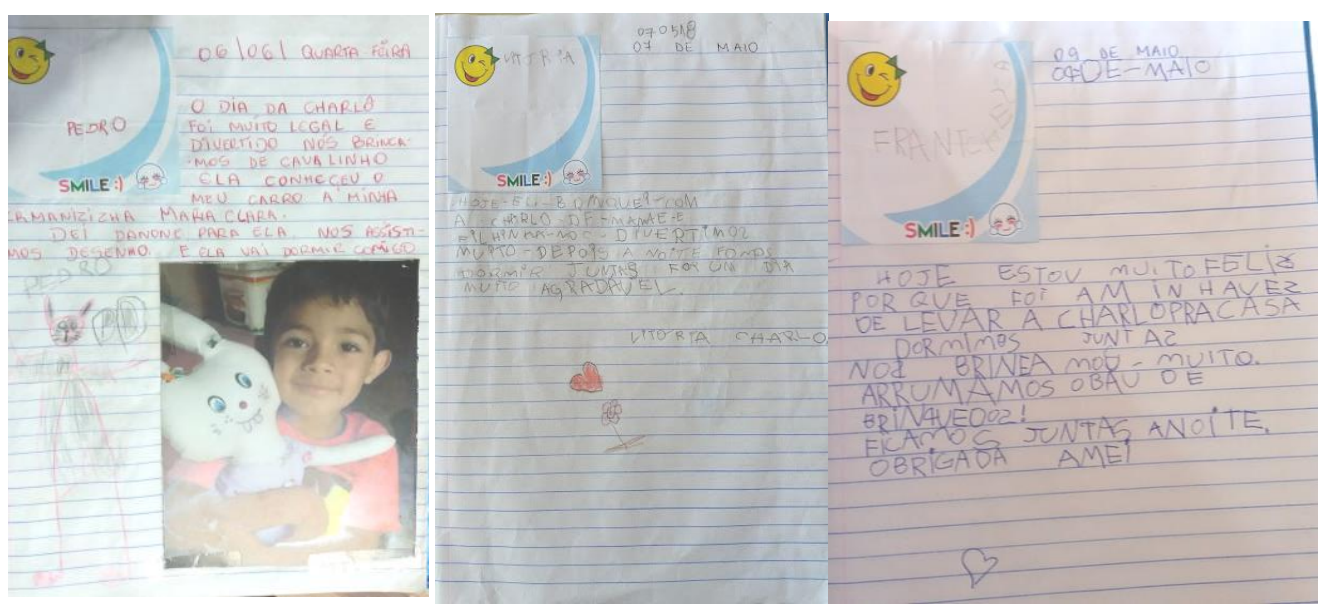

Fonte: Acervo pessoal das autoras

É válido ressaltar que os gêneros discursivos carta pessoal, diário e faz-de-conta infantil podem, quando vinculados às múltiplas práticas de letramento e diferentes identidades, propiciar também, segundo Martins (2003), a construção da subjetividade da criança juntamente com a construção da linguagem, tendo em vista que a maneira como a criança assume diferentes papeis sociais, atravessando diversos gêneros discursivos, é relevante para entender como ela se apropria das modalidades oral e escrita da linguagem (MARTINS; RANZANI - no prelo ).

\section{Refletindo sobre o processo de leitura e escrita}


A apropriação da linguagem em sua modalidade escrita na Educação Infantil sempre foi algo polêmico, a discussão sobre a alfabetização ou não alfabetização das crianças dessa etapa da Educação Básica suscita uma controvérsia desnecessária que não contribui para a questão do desenvolvimento da linguagem da criança, pois "o trabalho com as linguagens oral e escrita só tem sentido quando realizado com discursos reais e significativos. Isto é, com discursos que realmente se dirijam a alguém e que tenham uma finalidade enunciativa" (BRASIL, 2016b, p. 19).

Devemos considerar que as crianças têm contato com a linguagem escrita mesmo antes de saberem ler e escrever convencionalmente, pois ela está presente em diversas situações cotidianas, ainda que de maneiras distintas e com diversos significados entre os grupos sociais. À Educação Infantil, como primeira etapa da Educação Básica, cabe, portanto ampliar essas experiências culturais, socializando os saberes e conhecimentos previamente adquiridos, favorecendo a expressão das crianças em diferentes linguagens (Figura 1).

Figura 19 - A relação entre mediação e a construção das linguagens

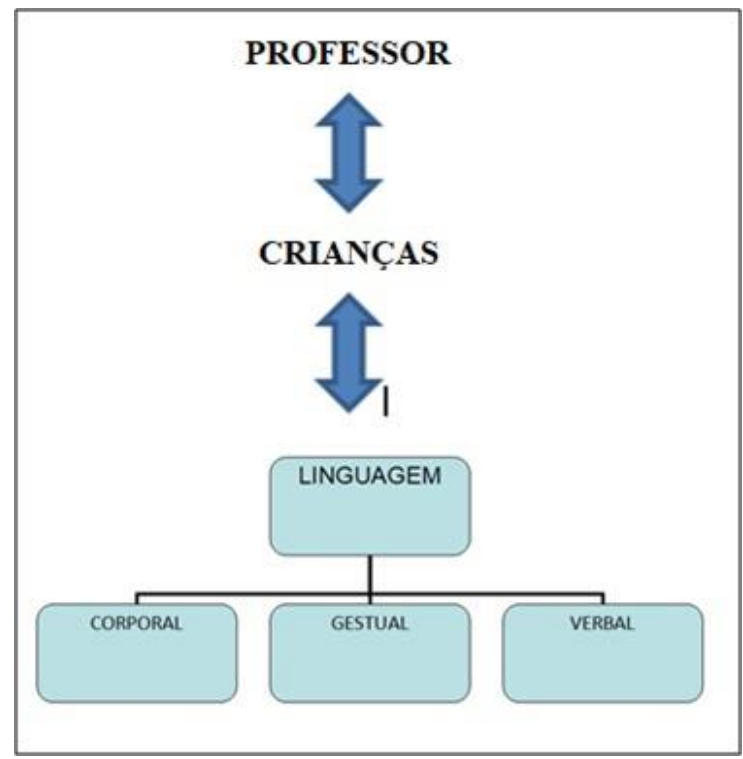

Fonte: As próprias autoras

$\mathrm{Na}$ escola, o professor faz uso de elementos mediadores para criar condições, de modo a aprendizagem tornar-se efetiva. Para tanto, pode utilizar práticas pedagógicas intencionalmente planejadas, a fim de seus alunos apropriarem-se dos conhecimentos e conceitos científicos sistematizados nos conteúdos curriculares. Nessa ação, a mediação do professor põe-se entre as crianças e o conhecimento para possibilitar a aprendizagem (PEREIRA, 2016). 
Diante disso, o ensino deve ter um significado e um sentido para as crianças, de maneira a potencializar a aprendizagem. A mediação pode favorecer a atribuição de significado e sentido aos conteúdos a serem assimilados pelas crianças. Desse modo,

[...] o bom ensino precisa estar direcionado às funções psíquicas superiores que ainda estão por se completar, portanto o papel do professor mediador é essencial. O professor não pode se prender ao nível de maturação da criança, mas sim antecipar-se ao desenvolvimento (NACANALLO; MORI, 2008, p. 7).

Dessa maneira, ao refletir sobre uma organização de ensino para a Educação Infantil, cujas faixas etárias compreendem crianças entre 4 a 6 anos, tendo como referência a abordagem histórico-cultural, não podemos deixar de considerar o papel da mediação e a importância da motivação das crianças nos processos educativos (PEREIRA, 2016).

Diante disso,

As práticas com a linguagem oral e com a linguagem escrita a serem efetivadas na Educação Infantil, pensadas a partir dessa perspectiva, consideram as interações verbais, tanto na modalidade oral quanto na escrita, como um fenômeno social que ocorre a partir das condições concretas de vida das crianças. Significa, em outras palavras, reconhecer que as crianças se constituem como seres de linguagem, nas interações que estabelecem com o mundo. Uma prática pedagógica pautada nessa perspectiva discursiva de apropriação da linguagem verbal exige não apenas conhecer os usos que os meninos e as meninas fazem da linguagem oral e da linguagem escrita, dentro e fora das instituições educativas, no seu cotidiano, mas, sobretudo, significa incorporar esses usos no planejamento didático e nas situações de aprendizagem a serem propostas. (BRASIL, 2016b, p. 19)

Nesse sentido, o projeto de letramento pode tornar a escrita mais significativa, tendo em vista que propicia uma grande variedade de situações de leitura e registro de experiências através da escrita, além de levar o professor a assumir uma posição de professor/ pesquisador, segundo Martins (2008). Independentemente de seu tema ou objetivo, ele tem "potencial para mobilizar conhecimentos, experiências, capacidades, estratégias, recursos, materiais e tecnologias de uso de língua escrita de diversas instituições cujas práticas letradas proporcionam os modelos de uso de textos aos alunos.” (KLEIMAN, 2007, p. 16).

Segundo Kleiman (2000, p. 238):

O projeto de letramento é uma prática social em que a escrita é utilizada para atingir algum outro fim, que vai além da mera aprendizagem da escrita (aprendizagem dos aspectos formais apenas), transformando objetivos circulares como "escrever para aprender a escrever" e "ler para aprender a ler" em ler e escrever para compreender e aprender aquilo que for relevante para o desenvolvimento e a realização do projeto. 
Enquanto modelo didático alternativo, o projeto de letramento inclui uma sequência didática ${ }^{3}$ por agrupamento de gêneros discursivos que possibilita uma "educação significativa para a vida" (TINOCO, 2008, p. 177-178), pois permite o desenvolvimento de diversas competências (linguística, enunciativa e discursiva) a partir de práticas sociais da escrita. Isso fica bastante evidenciado no projeto desenvolvido seja em relação às cartas trocadas entre diferentes turmas, seja no preenchimento do diário dos personagens Felpo e Charlô realizado com as famílias.

\section{Considerações finais}

As crianças das duas turmas se envolveram bastante durante as atividades, produzindo cartas, bilhetes, diários, postando fotos e mensagens no Facebook, enfim, evidenciando ser possível o trabalho de letramento na educação infantil, desde que sejam propostas práticas orais e escritas significativas.

As atividades de letramento na Educação Infantil, literárias ou não literárias, podem ser instrumentos para essa luta constante, tanto contra a opressão, quanto contra a desigualdade social, consoante palavras de Paulo Freire, ainda que não sejam os únicos.

Ao levar o Felpo ou a Charlô e seus respectivos diários para casa, as crianças puderam vivenciar e compartilhar experiências com a família e, posteriormente, com os amigos na escola. Ademais, foram motivadas a ler, ouvir para aprender, conhecer, ou seja, transformando suas experiências em atividades, conforme a definição de Leontiev (1978a, 1978b, 2014a, 2014b). Entretanto, sublinhamos que essas vivências também precisam e podem ser viabilizadas dentro da escola para que as crianças possam interagir com outras pessoas/ leitores/ contadores de histórias e possam também aventurar-se por diferentes práticas de leitura e escrita de forma ativa, sentindo-se letradas e assumindo diversos lugares e papéis sociais.

\section{REFERÊNCIAS}

BAKHTIN, M. Estética da criação verbal. 2 ed. São Paulo: Martins Fontes, 1997.

BRASIL. Diretrizes Curriculares Nacionais para a Educação Infantil. Secretaria de Educação Básica. Brasília: MEC, SEB, 2010.

${ }^{3}$ Definida por Dolz; Noverraz; Schneuwly como "um conjunto de atividades escolares organizadas, de maneira sistemática, em torno de um gênero oral ou escrito." (2004, p. 97) 
BRASIL. Ser criança na educação infantil: infância e linguagem. Ministério da Educação, Secretaria de Educação Básica. - 1.ed. - Brasília: MEC /SEB, 2016.

BRASIL. Crianças como leitoras e autoras. Ministério da Educação, Secretaria de Educação Básica. - 1.ed. Brasília: MEC /SEB, 2016b. 128 p.

BRASIL. Base Nacional Curricular Comum: Educação é a base. Ministério da Educação. 2018. Disponível em: http://basenacionalcomum.mec.gov.br. Acesso em: 3 jun. 2018.

FURNARI, E. Felpo Filva. São Paulo: Editora Moderna, 2006.

KLEIMAN, A. B. O processo de aculturação pela escrita: ensino da forma ou aprendizagem da função? In: KLEIMAN, A. B.; SIGNORINI, I. O ensino e a formação do professor: alfabetização de jovens e adultos. Porto Alegre: ARTMED, 2000. p. 223-243.

LEONTIEV, A. N. Actividade, Consciência e Personalidade. (Trad. Maria Sílvia Cintra Martins), 1978a. Disponível em:

http://marxists.anu.edu.au/portugues/leontiev/1978/activ_person/index.htm. Acesso em: 08 maio 2016.

LEONTIEV, A. N. O desenvolvimento do psiquismo. Lisboa: Livros Horizonte, 1978b.

LEONTIEV, A. N. Uma contribuição à teoria do desenvolvimento da psique infantil. In: VIGOTSKII, L. S., LURIA A. R., LEONTIEV, A. N. Linguagem, desenvolvimento e aprendizagem. São Paulo: Ícone, 2014a. p. 59-83.

LEONTIEV, A. N. Os princípios psicológicos da brincadeira pré-escolar. In: VIGOTSKII, L. S., LURIA A. R., LEONTIEV, A. N. Linguagem, desenvolvimento e aprendizagem. São Paulo: Ícone, 2014b. p. 119-142.

MARTINS, M. S. C. Linguagem, exercício de papeis e construção da subjetividade no universo cognitivo infantil. Tese (Doutorado in Linguística e Língua Portuguesa). Faculdade de Ciências e Letras, UNESP, Araraquara, 2003.

MARTINS, M. S. C. Oralidade, escrita e papéis sociais na infância. Campinas, SP: Mercado de Letras, 2008.

MARTINS, M. S. C.; RANZANI, A. Atividades de letramento com livros de literatura na Educação Infantil. (no prelo).

NACANALLO, L.F.; MORI, N.N.R. Jogos em matemática: uma possibilidade de desenvolvimento de funções psicológicas superiores. In: Seminário de Pesquisa, 2008, Londrina. Anais.... Londrina, 2008. Disponível em:

www.ppe.uem.br/publicacoes/seminario_ppe_2008/pdf/c025.pdf. Acesso em: 06 set. 2015.

PEREIRA, P. O uso de jogos e a mediação do professor na abordagem histórico-cultural: primeiras aproximações. 2016. 297 p. Dissertação (Mestrado em Educação) - Universidade Federal de São Carlos: UFSCar, 2016. 
SCHNEUWLY, B., Gêneros e tipos de discurso: considerações psicológicas e ontogenéticas. In: SCHNEUWLY, B., DOLZ, J. Gêneros orais e escritos na escola. (trad. Roxane Rojo e Glaís Sales Cordeiro). Campinas, SP: Mercado de Letras, 2004. p. 21-39.

TINOCO, G. M. A. M. Projetos de letramento: ação e formação de professores de língua materna. Tese (Doutorado in Linguística Aplicada). Instituto de Estudos da Linguagem, Unicamp, Campinas, 2008.

VYGOTSKI, L. S. Desarrollo del lenguaje oral. In: Obras escogidas. Tomo III. (Trad. Lydia Kuper) Madrid: Visor, 1995.

\section{Como referenciar este artigo}

RANZANI, A.; PEREIRA, P. Projeto de letramento na educação infantil: práticas orais e escritas. Temas em Educ. e Saúde, Araraquara, v. 14, n. 2, p. 302-317, jul./dez., 2018. eISSN 2526-3471. DOI: 10.26673/tes.v14i2.11902

Submetido em: 15/09/2018

Aprovado em: 28/10/2018 